\title{
Effects of ChondroT on potassium Oxonate- induced Hyperuricemic mice: downregulation of xanthine oxidase and urate transporter 1
}

Dool-Ri Oh ${ }^{1,2}$, Jong Ro Kim ${ }^{3}$, Chul Yung Choi ${ }^{2}$, Chan-hun Choi ${ }^{4}$, Chang-su Na ${ }^{4}$, Bok Yun Kang ${ }^{1}$, Seon-Jong $\mathrm{Kim}^{4,5^{*}}$ and Young Ran $\mathrm{Kim}^{1 *}$

\begin{abstract}
Background: ChondroT, a new herbal medication, consists of the water extracts of Osterici Radix, Lonicerae Folium, Angelicae Gigantis Radix, Clematidis Radix, and Phellodendri Cortex (6:4:4:4:3). We previously reported that ChondroT showed significant anti-arthritis and anti-inflammatory effects.

Methods: This study was designed to evaluate the effect of ChondroT on hyperuricemia. First, the effect of ChondroT was evaluated on xanthine oxidase (XOD) activity in vitro. The anti-hyperuricemic effect of ChondroT was also studied in potassium oxonate (PO)-induced hyperuricemic model mice. Uric acid (UA) and XOD were evaluated in the serum, urine, and liver of the mice. In addition, we measured serum creatinine $(\mathrm{Cr})$ and blood urea nitrogen (BUN) levels as well as mRNA expression of the mouse urate transporter 1 (mURAT1) to evaluate kidney function and urate excretion in hyperuricemic mice.

Results: ChondroT showed in vitro XOD inhibitory activity in a dose-dependent manner $(P<0.05)$. We demonstrated that ChondroT (37.5, 75 and $150 \mathrm{mg} / \mathrm{kg})$ significantly reduced serum UA $(P<0.01$ and $P<0.001$, respectively), and upregulated urinary UA $(P<0.001$, respectively) in PO-induced hyperuricemic mice. In addition, ChondroT (75 and $150 \mathrm{mg} / \mathrm{kg})$ significantly reduced $\mathrm{Cr}(P<0.05$ and $P<0.01$, respectively), BUN $(P<0.05$ and $P<0.001$, respectively), GOT $(P<0.05$ and $P<0.01$, respectively), and GPT $(P>0.05$ and $P<0.05$, respectively) levels in $P O$-induced hyperuricemic mice. ChondroT $(75$ and $150 \mathrm{mg} / \mathrm{kg})$ also significantly downregulated serum $(P<0$. $05)$ and liver $(P<0.05)$ XOD activity. Compared to the hyperuricemic mice, the ChondroT (37.5, 75, and 150 $\mathrm{mg} / \mathrm{kg}$ )-treated mice showed decreased mURAT1 protein expression level.
\end{abstract}

Conclusion: ChondroT displayed anti-hyperuricemic effects by regulating XOD activity and kidney mURAT1.

Keywords: ChondroT, Hyperuricemia, URAT1, Uric acid, Xanthine oxidase

\section{Background}

Hyperuricemia is characterized by an increase in blood uric acid (UA) levels [1]. UA is the last metabolite in the purine catabolic pathway formed by the enzyme xanthine oxidase (XOD). The high blood UA levels cause the accumulation of urate crystals in the joints, which is known as

\footnotetext{
*Correspondence: mofoster@daum.net; kimyr@chonnam.ac.kr

${ }^{4}$ College of Korean Medicine, Dongshin University, 185 Geonjae-ro, Naju-si, Jeollanam-do 58245, Republic of Korea

${ }^{1}$ College of Pharmacy and Research Institute of Drug Development, Chonnam National University, Gwangju 61186, Republic of Korea Full list of author information is available at the end of the article
}

an important risk factor for gouty arthritis, UA nephrolithiasis, and kidney disease [2]. In humans, $90 \%$ of the filtered urate is reabsorbed, which is mediated by specific transporter molecule such as urate transporter 1 (URAT1). It functions as the major mechanism for regulating blood urate levels. It has also been reported that a defect in human URAT1 (hURAT1) is associated with the pathogenesis of hyperuricemia and gout $[3,4]$. Thus, XOD and URAT1 are important targets to regulate hyperuricemia and gout. Potassium oxonate-induced hyperuricemic mice are appropriate experimental models

(c) The Author(s). 2019 Open Access This article is distributed under the terms of the Creative Commons Attribution 4.0 International License (http://creativecommons.org/licenses/by/4.0/), which permits unrestricted use, distribution, and reproduction in any medium, provided you give appropriate credit to the original author(s) and the source, provide a link to the Creative Commons license, and indicate if changes were made. The Creative Commons Public Domain Dedication waiver (http://creativecommons.org/publicdomain/zero/1.0/) applies to the data made available in this article, unless otherwise stated. 
for investigating the mechanism underlying hyperuricemia and for developing therapeutic agents. Allopurinol (AP) is an anti-hyperuricemic agent that acts by reducing XOD activity and serum UA levels. However, allopurinol may cause serious side effects such as skin rashes, allergic reactions [5], and gastrointestinal toxicity [6]. Therefore, there is an obvious need for novel agents for the physiological regulation of UA levels and prevention of hyperuricemia.

Gangwhaljetongyeum (GHJTY), a traditional Korean herbal medicine composed of 18 herbs, has been used to treat severe joint pain, limited motion, fever, and swelling [7]. We previously reported that GHJTY inhibited the inflammatory processes associated with arthritis [8]. Using bioinformatics analysis [9] and screening experiments, we selected the following five effective herbal constituents of GHJTY, Osterici Radix, Lonicerae Folium, Angelicae Gigantis Radix, Clematidis Radix, and Phellodendri Cortex and named the resulting concoction as ChondroT [10]. ChondroT showed more significant multifunctional therapeutic effects on inflammation and arthritis than GHJTY did [10]. Some reports have shown the strong correlation between serum urate levels and generalized osteoarthritis $[11,12]$. UA elevations may be evaluated as a major risk factor for osteoarthritis tissue damage, osteoarthritis progression, or both through inflammasome activation $[13,14]$. In the present study, we investigated the effects of ChondroT on in vitro and in vivo the xanthine oxidase activity as well as its anti-hyperuricemia effects in PO-induced hyperuricemic mice.

\section{Methods}

\section{Materials and reagents}

The XOD, xanthine, allopurinol (AP), and PO were purchased from Sigma-Aldrich (St. Louis, MO, USA). The UA and XOD assay kits were purchased from Cayman Chemical (Ann Arbor, MI, USA) and Biovision (Mountain View, CA, USA), respectively.

ChondroT was prepared using a method previously described [10]. The five herbal medicines forming ChondroT were purchased from Omniherb (Yeongcheon, Korea). Briefly, the five herbal constituents, Osterici Radix (Korea), Lonicerae Folium (China), Angelicae Gigantis Radix (Korea), Clematidis Radix (China), and Phellodendri Cortex (China) were combined in a ratio of 6:4:4:4:3 (Table 1). Next, each five herbal constituents as well as ChondroT extracted once using a 10-fold volume of water as the solvent at $100{ }^{\circ} \mathrm{C}$ for $3 \mathrm{~h}$. After filtration (180-mesh), the water extract was concentrated using a continuous vacuum evaporator (at approximately $55-60{ }^{\circ} \mathrm{C}, 670 \mathrm{mmHg}$ ), followed by lyophilization using a vacuum drier $(720 \mathrm{mmHg})$ for $8 \mathrm{~h}$. The extraction yield of ChondroT was about 29.5\%. The resultant ChondroT and each herbal constituents was dissolved in phosphate-
Table 1 Composition of ChondroT and the used parts of 5 herbs

\begin{tabular}{llll}
\hline Latin name & Scientific name & $\begin{array}{l}\text { Used } \\
\text { part }\end{array}$ & $\begin{array}{l}\mathrm{w} / \mathrm{w} \\
\%\end{array}$ \\
\hline $\begin{array}{l}\text { Angelicae Gigantis } \\
\text { Radix }\end{array}$ & Angelica gigas Nakai & root & 19.0 \\
Clematidis Radix & $\begin{array}{l}\text { Clematis mandshurica } \\
\text { Ruprecht }\end{array}$ & root & 19.0 \\
$\begin{array}{l}\text { Lonicerae Folium } \\
\text { Osterici Radix }\end{array}$ & $\begin{array}{l}\text { Oonicera japonica Thunberg } \\
\text { Oaxicum koreanum }\end{array}$ & leaf & 19.0 \\
Phellodendri Cortex & $\begin{array}{l}\text { Phellodendron amurense } \\
\text { Ruprecht }\end{array}$ & tree bark & 14.3 \\
\hline
\end{tabular}

buffered saline (PBS) and filter-sterilized. For phytochemical analysis for ChondroT extract used in this study, a convenient and accurate HPLC-PDA detection was previously conducted for simultaneous determination of seven reference components, chlorogenic acid, berberine $\mathrm{Cl}$, nodakenin, isoferulic acid, oxypeucedanin hydrate, decursin, and decursinol angelate [10].

\section{Evaluation of in vitro XOD inhibitory activity}

XOD activity were measured by modified procedure protocol of Wang et al. (2008) [15]. ChondroT at concentrations of 100,300 , and $500 \mu \mathrm{g} / \mathrm{mL}$ was added to $0.1 \mathrm{M}$ potassium phosphate buffer ( $\mathrm{pH} 7.5)$ containing $0.4 \mathrm{U} / \mathrm{mL} \mathrm{XOD}$ and then incubated for $10 \mathrm{~min}$ at $37^{\circ} \mathrm{C}$. The xanthine substrate $(0.4 \mathrm{mM})$ was added to the test solutions, which were incubated for $10 \mathrm{~min}$ at $37^{\circ} \mathrm{C}$, and then the absorbance of each sample was measured at $295 \mathrm{~nm}$. AP was used as a positive control at a final concentration of $1.36 \mu \mathrm{g} / \mathrm{ml}$. The XOD inhibitory activity was expressed as the percentage inhibition of XOD in the assay mixture system.

\section{Experimental mice and treatments}

Five week old male ICR mice weighing 25-30 g were purchased from Orient Bio (Seongnam, Republic of Korea). The specific-pathogen free (SPF) mice were randomly divided into 6 groups $(N=5)$. The animals were maintained at a constant room temperature of $22 \pm 2{ }^{\circ} \mathrm{C}$ with a humidity of $50 \pm 5 \%$ and were allowed free access to water and food under a 12-h light/dark cycle (lights on at 8:00 a.m.). All the animal procedures were carried out in accordance with the guidelines of the Animal Care and Use Committee of Chonnam National University. The animal study was approved by Animal Care and Use Committee of Chonnam National University (Permission number: CNN IACUC-YB-2016-12). After the experiment, all animals were euthanized using Carbon dioxide $\left(\mathrm{CO}_{2}\right)$ in accordance with the Institutional Animal Care and Use Committee (IACUC) guidelines. 


\section{Experimental model of hyperuricemia in mice and drug} administration

The hyperuricemic animal model was established by injecting the animals with $\mathrm{PO}$, a urate oxidase inhibitor $[16,17]$. PO were administrated according to previously described method [18], with modifications. Briefly, the mice were divided into six groups of five mice each, and ChondroT was orally pre-administered at doses of $37.5,75$, and $150 \mathrm{mg} / \mathrm{kg} /$ day for 7 days before the PO administration. And then, all the mice except those in the normal control group were intraperitoneally injected once daily with $\mathrm{PO}(300 \mathrm{mg} / \mathrm{kg})$ at 10:00 a.m. for 7 days experiment. The PO was dissolved in $0.9 \%$ saline solution before use. ChondroT $(37.5,75$, and $150 \mathrm{mg} / \mathrm{kg}$ ) and AP $(5 \mathrm{mg} / \mathrm{kg})$ were orally administration at 11:00 a.m. for 7 consecutive days on the day when the PO was given. Two hours after the final drug administration, all animals were anesthetized using $2.5 \%$ isoflurane. Blood samples were collected from the abdominal aorta of the mice and then the samples were centrifuged at $3000 \mathrm{~g}$ for $10 \mathrm{~min}$. The supernatant serum and urine samples were both collected and stored at $-20^{\circ} \mathrm{C}$ until they were assayed. The mouse kidneys and livers were collected, washed with $0.9 \%$ cold saline solution, and stored at $-80^{\circ} \mathrm{C}$ until they were assayed.

\section{Biochemical analysis of hyperuricemic mice}

The serum sample was assayed to determine the levels of UA, creatinine $(\mathrm{Cr})$, blood urea nitrogen $(\mathrm{BUN})$, glucose, glutamic oxaloacetic transaminase (GOT), and glutamic pyruvic transaminase (GPT) using appropriate kits (DRI-CHEM 4000i, FUGI-FILM, Tokyo, Japan) [19, 20]. The levels of UA were measured in the collected urine samples using Cayman Chemical assay kits (Cayman, Ann Arbor, MI, USA). The serum and liver XOD activities were determined using a fluorometric assay kit (Biovision, Mountain View, CA, USA) in accordance with the manufacturer's protocol.

\section{Reverse transcription-polymerase chain reaction (RT-PCR)}

Total RNA was isolated from the mouse kidney cortex tissue using an easy-BLUE total RNA extraction kit (iNtRON Biotechnology, Seongnam, Republic of Korea) according to the manufacturer's instructions. The final total RNA pellet was resuspended in $20 \mu \mathrm{L}$ of diethyl pyrocarbonate-treated water. To synthesize the cDNA, $1 \mu \mathrm{g}$ total RNA was mixed with a premix containing the oligo (dT) primer and diethyl pyrocarbonate-treated water in a final volume of $20 \mu \mathrm{L}$ and incubated at $45^{\circ} \mathrm{C}$ for $60 \mathrm{~min}$. The reaction was stopped by heat inactivation at $95^{\circ} \mathrm{C}$ for $5 \mathrm{~min}$. Subsequently, the cDNA was amplified with gene-specific primers using the polymerase chain reaction (PCR) PreMix (Bioneer, Daejeon, Republic of Korea) according to the manufacturer's instructions.
The specific primers used in this study are shown in Table 2. RT-PCR analysis were prepared according to previously described method $[19,20]$, with modifications. Briefly, $5 \mu \mathrm{L}$ of $\mathrm{cDNA}, 1 \mu \mathrm{L}$ of forward primer $(10 \mathrm{pm}), 1 \mu \mathrm{L}$ of reverse primer $(10 \mathrm{pm}), 13 \mu \mathrm{L}$ of diethyl pyrocarbonate-treated water were added to PCR PreMix tube on ice. Thirty cycles of amplification were performed with denaturation at $95^{\circ} \mathrm{C}$ for $30 \mathrm{~s}$, annealing at $58{ }^{\circ} \mathrm{C}$ for $40 \mathrm{~s}$, and extension at $72^{\circ} \mathrm{C}$ for $50 \mathrm{~s}$. All reactions were finished with a single extra cycle at $72^{\circ}$ $\mathrm{C}$ for ten minutes. The PCR products were electrophoresed on a $1.5 \%(w / v)$ agarose gel, stained with ethidium bromide, and then the expression levels were quantified using a gel documentation and analysis system (Gel Doc 2000, Bio-Rad, Sydney, Australia). The relative expression levels of the target genes were normalized to a glyceraldehyde 3-phosphate dehydrogenase (GAPDH) internal control.

\section{Statistical analysis}

The data are presented as the mean \pm standard error (S.E.) and were statistically evaluated using one-way analysis of variance (ANOVA) using the GraphPad Prism (GraphPad Inc., San Diego, California, USA) software program. The results were considered statistical significance at $P<0.05$.

\section{Results}

\section{Effects of ChondroT on in vitro XOD inhibitory activity}

ChondroT at concentrations of 100,300 , and $500 \mu \mathrm{g} / \mathrm{mL}$ inhibited XOD activity in a dose-dependent manner by $26.94 \pm 1.80 \%, 46.11 \pm 5.26 \%$, and $65.04 \pm 7.41 \%$, respectively, with a half maximal inhibitory concentration $\left(\mathrm{IC}_{50}\right)$ of $414.09 \mu \mathrm{g} / \mathrm{mL}$. The positive control, AP, which is an established XOD inhibitor showed an inhibition of $95.53 \pm 0.13 \%$ at a concentration of $1.36 \mu \mathrm{g} / \mathrm{mL}$ and $\mathrm{IC}_{50}$ of $0.21 \mu \mathrm{g} / \mathrm{mL}$ (Table 3 ).

\section{Effects of ChondroT on serum and urine UA in PO-induced hyperuricemic mice}

The anti-hyperuricemic effects of ChondroT were evaluated in PO-induced hyperuricemic mice by determining the UA and XOD levels in the serum, urine, and liver. Five week old male ICR mice (25-30 g) were randomly

Table 2 Primers and expected sizes of polymerase chain reaction $(P C R)$ products with each primer pair

\begin{tabular}{llll}
\hline Gene & Primer sequence $\left(5^{\prime} \rightarrow 3^{\prime}\right)$ & $\begin{array}{l}\text { Product } \\
\text { size }(\mathrm{bp})\end{array}$ & $\begin{array}{l}\text { GenBank } \\
\text { accession } \\
\text { number }\end{array}$ \\
\hline mURAT1 & $\begin{array}{l}\text { Forward: GCTACCAGAATCGGCACGCT } \\
\text { Reverse: CACCGGGAAGTCACAATCC }\end{array}$ & 342 & NM_009203 \\
GAPDH & $\begin{array}{l}\text { Forward: AGATCCACAACGGATACATT } \\
\text { Reverse: TCCCTCAAGATTGTCAGCAA }\end{array}$ & 309 & NM_008084 \\
\hline
\end{tabular}


Table 3 Effects of ChondroT on in vitro xanthine oxidase (XOD) activity

\begin{tabular}{lll}
\hline Drug & $\begin{array}{l}\text { Concentration } \\
(\mu \mathrm{g} / \mathrm{mL})\end{array}$ & $\begin{array}{l}\text { Inhibition } \\
(\% \text { Mean } \pm \text { S.E. })\end{array}$ \\
\hline Angelicae Gigantis Radix & 100 & $2.82 \pm 3.84$ \\
Clematidis Radix & 100 & $11.67 \pm 1.03$ \\
Lonicerae Folium & 100 & $22.10 \pm 3.72$ \\
Osterici Radix & 100 & $8.62 \pm 1.43$ \\
Phellodendri Cortex & 100 & $19.01 \pm 2.41$ \\
ChondroT & 100 & $26.94 \pm 1.80^{*}$ \\
& 300 & $46.11 \pm 5.26^{*}$ \\
& 500 & $65.04 \pm 7.41^{*}$ \\
Allopurinol & 1.36 & $95.53 \pm 0.13^{* * *}$
\end{tabular}

Values are mean \pm standard error (S.E., $n=3$ ). ${ }^{*} P<0.05$ and ${ }^{* * *} P<0.001$ compared with negative control group

divided into 6 groups $(N=5)$. The serum UA significantly increased in the PO-induced hyperuricemic mice compared to that in the negative control (NC) mice (Fig. 1a). AP ( $5 \mathrm{mg} / \mathrm{kg})$ reduced the serum UA levels of the hyperuricemic group more significantly than that of the NC group. Treatment with ChondroT (37.5, 75, and 150 $\mathrm{mg} / \mathrm{kg}$ ) decreased the serum UA in hyperuricemic mice $(P<0.01$ or $P<0.001$, Fig. 1a). In addition, AP $(5 \mathrm{mg} / \mathrm{kg})$ and ChondroT (37.5, 75, and $150 \mathrm{mg} / \mathrm{kg}$ ) effectively increased the urinary level of UA $(P<0.01$ or $P<0.001$, Fig. 1b), suggesting an increased excretion of UA from blood into urine. These data suggest that ChondroT may enhance kidney urate excretion in hyperuricemic mice.

\section{Effects of ChondroT on XOD activity in hyperuricemic mice}

The effects of ChondroT on in vivo XOD activity were evaluated in PO-induced hyperuricemic mice. Figure 2 shows the effects of ChondroT and AP on serum and liver XOD activity in hyperuricemic mice. AP significantly suppressed the serum and liver XOD activity in hyperuricemic mice $(P<0.001$ or $P<0.01$, respectively). ChondroT (75 and $150 \mathrm{mg} / \mathrm{kg}$ ) significantly inhibited the serum XOD activity $(P<0.05$, Fig. 2a). We observed a similar inhibition of the liver XOD activity by ChondroT (75 and $150 \mathrm{mg} / \mathrm{kg}, P<0.05$, Fig. $2 \mathrm{~b}$ ).

\section{Effects of ChondroT on liver and kidney function of hyperuricemic mice}

The serum biochemical parameters of each group are shown in Table 4. To evaluate the protective effects of ChondroT on kidney toxicity in the hyperuricemic mice, serum toxicological markers indicative of kidney injury were measured at the end of the experimental period. The serum levels of $\mathrm{Cr}$ and BUN significantly increased in the PO-induced hyperuricemic mice compared with that in the NC group, while treatment with ChondroT (75 and

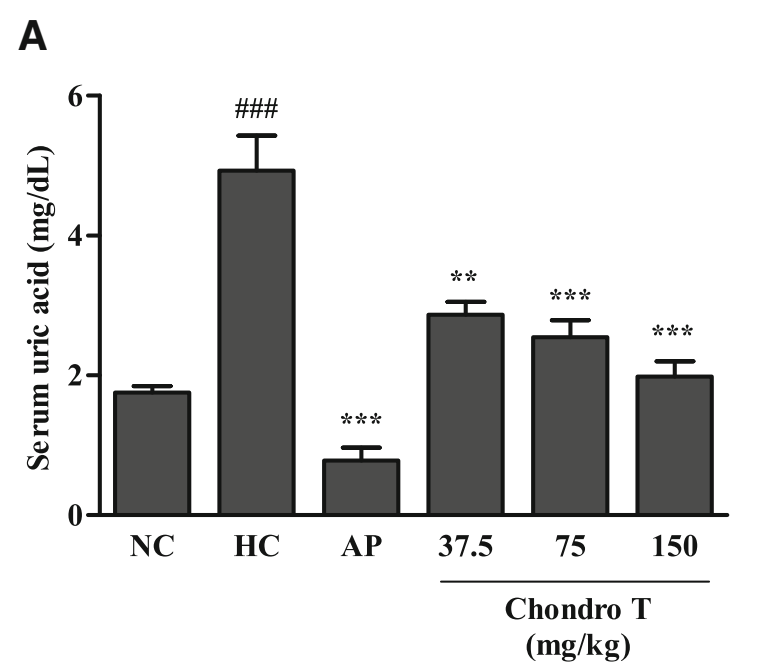

B

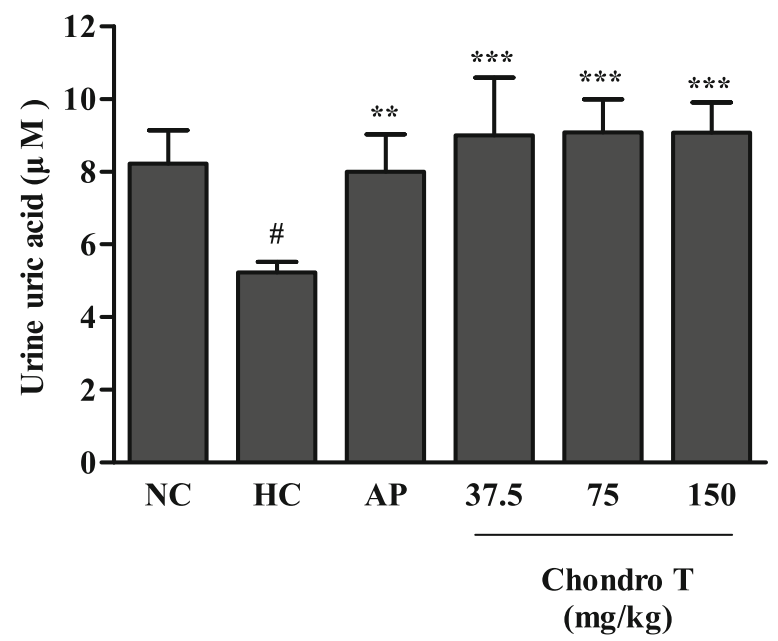

Fig. 1 Effects of ChondroT on uric acid in (a) serum and (b) urine of potassium oxonate (PO)-induced hyperuricemic mice NC, normal control; $\mathrm{HC}$, hyperuricemic control with potassium oxonate (300 $\mathrm{mg} / \mathrm{kg})$; AP, allopurinol $(5 \mathrm{mg} / \mathrm{kg})$. Values are expressed as the mean \pm standard error (S.E., $n=5) .{ }^{\#} P<0.05$ and ${ }^{\# \# \#} P<0.001$ compared with NC group; ${ }^{* *} P<0.01$, and ${ }^{* *} P<0.001$ compared with HC group

$150 \mathrm{mg} / \mathrm{kg}$ ) decreased the levels. The ChondroT (37.5, 75, and $150 \mathrm{mg} / \mathrm{kg}$ ) also significantly reduced the serum BUN levels in hyperuricemic mice. Furthermore, ChondroT alleviated the liver damage by lowering the levels of GOT and GPT, two common markers of liver damage, which were in turn increased by the PO treatment.

\section{Effects of ChondroT on mRNA expression of mURAT1 in} hyperuricemic mice

URAT1 is an important gene involved in the transport of UA from the kidney to the blood. To confirm the 


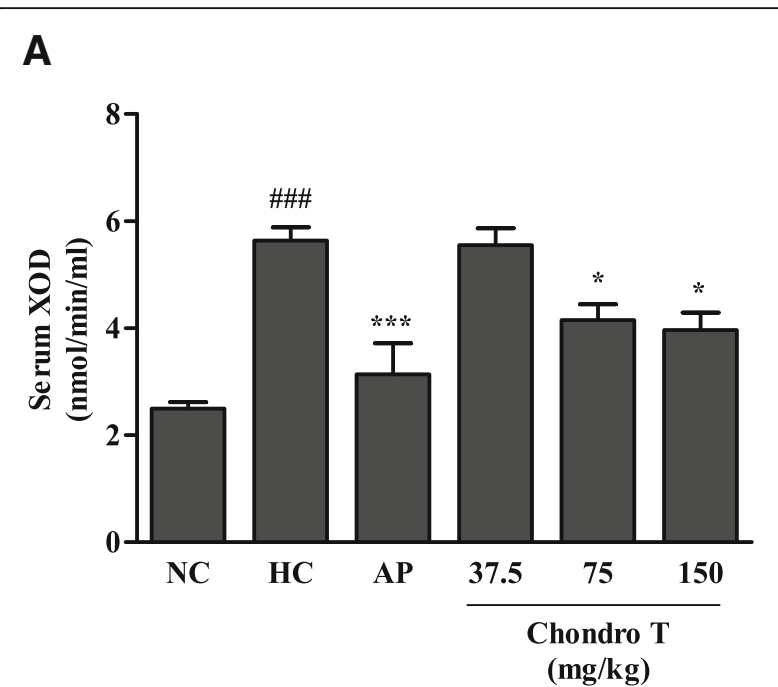

B

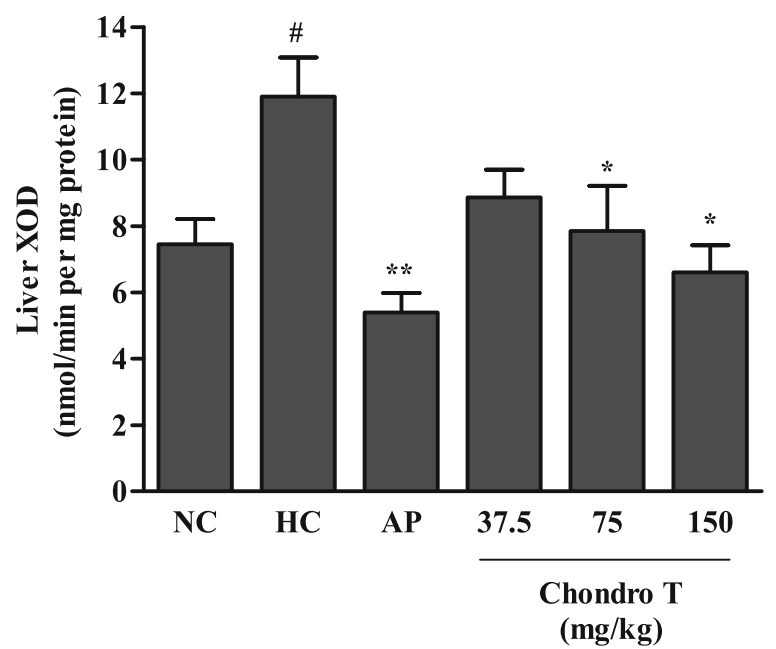

Fig. 2 Effects of ChondroT on (a) serum and (b) liver xanthine oxidase (XOD) activities of potassium oxonate (PO)-induced hyperuricemic mice NC, normal control; $\mathrm{HC}$, hyperuricemic control with potassium oxonate (300 mg/kg); AP, allopurinol $(5 \mathrm{mg} / \mathrm{kg})$. Values are expressed as the mean \pm standard error (S.E., $n=5) .{ }^{\#} P<0.05$ and ${ }^{\# \# \#} P<0.001$ compared with NC group; ${ }^{*} P<0.05,{ }^{* *} P<0.01$, and ${ }^{* * *} P<0.001$ compared with $\mathrm{HC}$ group

mechanism underlying the effects of ChondroT on hyperuricemia, the URAT1 gene expression levels in the kidney tissue were investigated (Fig. 3). Compared with the NC group, the hyperuricemic control (HC) group exhibited increased URAT1 mRNA levels in the kidney tissue. However, the URAT1 mRNA expression levels of the ChondroT $(37.5,75$ and $150 \mathrm{mg} / \mathrm{kg}, P<0.01$ and $P<$ $0.001)$-treated groups significantly decreased compared with that of the HC group (Fig. 3). These data suggest that ChondroT may enhance kidney urate excretion through the actions of URAT1 in hyperuricemic mice.

\section{Discussion}

In the present study, we demonstrated that ChondroT, a new complex herbal medication reduced serum UA in hyperuricemic mice by downregulating XOD activity and renal mURAT1. Because XOD and URAT1 are important targets to regulate hyperuricemia and gout, potassium oxonate-induced hyperuricemic mice were used as appropriate experimental models for investigating the mechanism underlying hyperuricemia. XOD plays an important role in the catabolism of purines. The XOD enzyme catalyzes the oxidation of hypoxanthine to xanthine and can further catalyze the oxidation of xanthine to UA. AP, an XOD inhibitor has been used as an anti-hyperuricemia agent and anti-gout [21]. In addition, febuxostat is a novel orally administered antihyperuricemic drug [22] that reduces the production of UA in the body by XOD inhibition [22, 23]. We demonstrated that ChondroT inhibited XOD activity in vitro (Table 3). PO-treated mice can serve as a useful animal model for investigating hyperuricemia pathology. The intraperitoneal administration of $300 \mathrm{mg} / \mathrm{kg}$ PO for 7 days to mice increased the serum UA, decreased the urinary UA, and elevated the serum and liver XOD activity (Figs. 1 and 2). ChondroT significantly reduced the serum UA level, whereas it increased the urinary UA level in hyperuricemic mice (Fig. 1). Moreover, the ChondroT-treated mice showed a significant decreased in serum and liver XOD activity compared with that of the hyperuricemic mice (Fig. 2). Thus, the in vivo enzyme inhibitory activity of ChondroT is the net inhibitory activity of both XOD and xanthine dehydrogenase (XDH).

Hyperuricemia is frequently observed in patients with chronic kidney disease and can be accompanied by an increase in serum $\mathrm{Cr}$ and BUN [24]. Previous other studies reported that AP significantly blocked renal functional changes in PO-induced hyperuricemic rats and lowered $\mathrm{Cr}$ levels as well as UA in patients $[25,26]$. We demonstrated that ChondroT significantly reduced the serum $\mathrm{Cr}$ and BUN levels in hyperuricemic mice (Table 4). Furthermore, liver dysfunction, poor blood flow in the liver and raised uric acid may cause hyperuricemia [27]. In this study, PO-induced hyperuricemic mice increased liver damages by increasing the levels of two markers for liver damages, GOT, and GPT, which was attenuated by ChondroT and AP.

Richette et al. [28] reported that more than $90 \%$ of all cases of hyperuricemia are caused by the impaired renal excretion of UA. Renal mURAT1, a urate transporter gene contributes significantly to the reabsorption of UA in humans. Furthermore, it is a drug target that is inhibited by uricosuric drugs such as benzbromarone and probenecid [28]. In this study, the PO-induced hyperuricemic mice showed increased expression 
Table 4 Effects of ChondroT on serum levels of Creatinine ( $\mathrm{Cr}$ ), blood urea nitrogen (BUN), glutamic oxaloacetic transaminase (GOT) and glutamic pyruvic transaminase (GPT) in hyperuricemic mice

\begin{tabular}{|c|c|c|c|c|c|c|}
\hline \multirow[t]{2}{*}{ Blood parameter } & \multirow[t]{2}{*}{$\mathrm{NC}$} & \multirow[t]{2}{*}{$\mathrm{HC}$} & \multirow{2}{*}{$\begin{array}{l}\text { AP }(\mathrm{mg} / \mathrm{kg}) \\
5\end{array}$} & \multicolumn{3}{|c|}{ ChondroT (mg/kg) } \\
\hline & & & & 37.5 & 75 & 150 \\
\hline Creatinine (mg/dL) & $0.20 \pm 0.02$ & $0.75 \pm 0.04$ \#\#\# & $0.23 \pm 0.011^{* *}$ & $0.50 \pm 0.04$ & $0.28 \pm 0.02^{*}$ & $0.23 \pm 0.02^{* *}$ \\
\hline BUN (mg/dL) & $23.62 \pm 0.56$ & $40.10 \pm 1.21$ \#\#\# & $21.45 \pm 0.96^{* * *}$ & $26.27 \pm 0.58^{*}$ & $22.95 \pm 1.06^{*}$ & $20.43 \pm 0.74^{* * *}$ \\
\hline GOT (U/L) & $48.67 \pm 0.90$ & $73.33 \pm 3.95$ \#\# & $39.80 \pm 0.92^{* * *}$ & $54.83 \pm 1.90^{*}$ & $46.00 \pm 2.01^{*}$ & $39.75 \pm 2.56^{* *}$ \\
\hline GPT (U/L) & $15.00 \pm 1.58$ & $28.00 \pm 1.46$ & $13.50 \pm 0.91^{*}$ & $24.17 \pm 0.95$ & $20.33 \pm 1.29$ & $15.00 \pm 1.39^{*}$ \\
\hline
\end{tabular}

$N C$, normal control; $H C$, hyperuricemic control with potassium oxonate $(300 \mathrm{mg} / \mathrm{kg}) ; A P$, allopurinol $(5 \mathrm{mg} / \mathrm{kg})$. Values are mean \pm standard error $(\mathrm{S} . \mathrm{E} ., \mathrm{n}=5)$. ${ }^{\# \#} P<$ 0.01 and ${ }^{\# \#} P<0.001$ compared with NC group; ${ }^{*} P<0.05,{ }^{* *} P<0.01$, and ${ }^{* * *} P<0.001$ compared with $\mathrm{HC}$ group

of mURAT1 mRNA, which was significantly attenuated by ChondroT treatment (Fig. 3). These results suggest that ChondroT likely plays a role in reducing urate reabsorption with the subsequent enhancement of urate excretion in hyperuricemic mice, mainly by the downregulation of mURAT1. However, the uricosuric effect of ChondroT could have limited clinical use due to safety issues such as risk of uric acid stone formation. Recently, Sun et al. [11] and Acheson et al. [12] reported the involvement of serum urate levels in osteoarthritis. The association between hyperuricemia and osteoarthritis might be explained by a common risk factor rather than any direct effect of serum urate on the joints. Thus, both studies found a significant relationship between the pathogenesis of osteoarthritis and serum UA levels.

In a previous study, we demonstrated that ChondroT triggered significant anti-inflammatory and anti-arthritis effects [10]. Previously, we evaluated the toxicity of ChondroT at high doses such as 500, 1000, and 2000 $\mathrm{mg} / \mathrm{kg}$ for 4 weeks at Korea Testing \& Research Institute (KTR). ChondroT was confirmed to be safe herb at
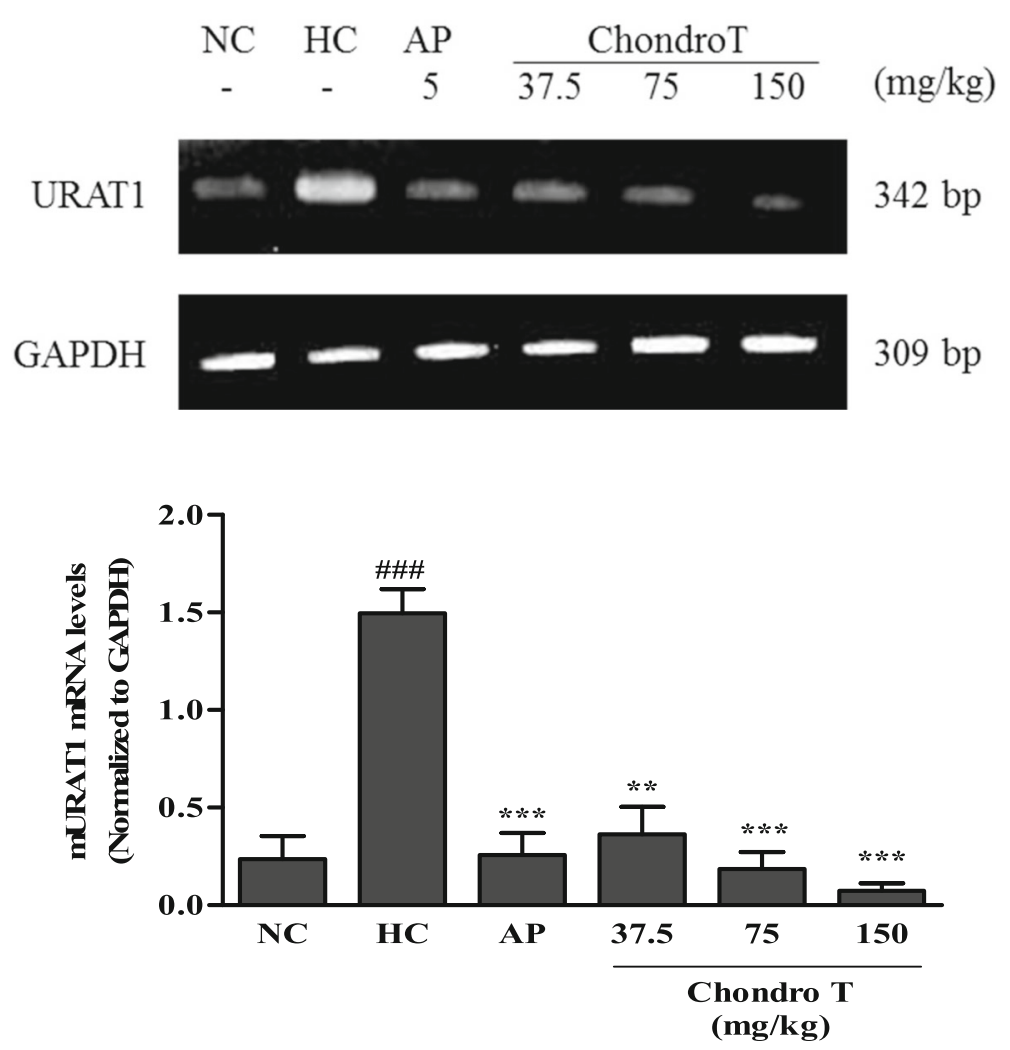

Fig. 3 Effects of ChondroT on mRNA levels of mouse urate transporter 1 (mURAT1) in kidney tissues of potassium oxonate (PO)-induced hyperuricemic mice using reverse transcription-polymerase chain reaction (RT-PCR). The relative mRNA expression levels of the mURAT1 gene were normalized against GAPDH NC, normal control; HC, hyperuricemic control with potassium oxonate (300 mg/kg); AP, allopurinol (5 mg/kg). Values are expressed as the mean \pm standard error $($ S.E., $n=5)$. ${ }^{\# \# \#} P<0.001$ compared with NC group ${ }^{* * *} P<0.01$ and ${ }^{* * * *} P<0.001$ compared with HC group 
the high doses. AST and ALT levels of ChondroT-treated rats are normal value ranges. In addition, BUN levels in ChondroT-treated rats are in normal scores. ChondroT did not show any toxicity to liver, kidney, heart, lung, and spleen in individual histopathologic evaluations (data not shown). In this present study, ChondroT displayed anti-hyperuricemic effects by regulating XOD activity and kidney mURAT1. ChondroT is a water extract of five herbs, Osterici Radix, Lonicerae Folium, Angelicae Gigantis Radix, Clematidis Radix, and Phellodendri Cortex. We confirmed that of the five herbs included in the extract, Lonicerae Folium and Phellodendri Cortex strongly inhibited XOD activity in vitro (Table 3). Furthermore, Phellodendri Cortex has been reported to decrease serum UA and liver XOD activity in PO-induced hyperuricemic mice [29]. In addition, Phellodendri Cortex was reported to protect human osteoarthritic cartilage and chondrocytes [30]. Moreover, Lonicerae Folium and Clematidis Radix showed inhibitory effects against XOD activity in vitro, but these effects were not strong [31]. Clematidis Radix also has been reported to show anti-rheumatic arthritis effects that are mediated through decrease $\mathrm{PLA}_{2}$ activities and $\mathrm{PGE}_{2}$ production and lipopolysaccharide-induced COX-2 protein expression [32]. ChondroT showed a more significant in vivo than in vitro inhibition of XOD (Table 3 and Fig. 2). In addition, ChondroT showed a higher synergistic effect than each of its five herbal constituents did on XOD (Table 3). These results suggest that ChondroT may be a promising therapeutic candidate for the treatment of hyperuricemiarelated diseases.

In our previous results, seven reference components in ChondroT, such as chlorogenic acid, berberine $\mathrm{Cl}$, nodakenin, isoferulic acid, oxypeucedanin hydrate, decursin, and decursinol angelate were selected for quality control of ChondroT [10]. Chlorogenic acid has been shown to exert anti-gout activity as well as improvement on hyperuricemia and inflammation by inhibiting the XOD activity, serum UA levels, and production of proinflammatory cytokines (e.g. IL-1 $\beta$ and IL-6) [33]. In addition, alkaloid compounds including berberine $\mathrm{Cl}$ have been shown inhibition activity of XOD enzymes to reduce UA levels [29, 34]. However, further studies are required to determine the functional active constituents that are involved in the anti-hyperuricemia as well as anti-gout activity.

\section{Conclusion}

These results showed that ChondroT regulates hyperuricemia by downregulating mURAT1 and inhibiting XOD enzyme. In addition, the suppressive effect on XOD enzyme in vivo was greater than that exhibited in vitro, suggesting that ChondroT, a new complex herbal medication, has therapeutic potential for the treatment of patients suffering from hyperuricemia and gout.

\section{Abbreviations}

AP: allopurinol; BUN: blood urea nitrogen; Cr: creatinine; GAPDH: glyceraldehyde3-phosphate dehydrogenase; GHJTY: Ganghwaljetongyeum; GOT: glutamic oxaloacetic transaminase; GPT: glutamic pyruvic transaminase; PO: potassium oxonate; RT-PCR: reverse transcription-polymerase chain reaction; UA: uric acid; URAT1: urate transporter 1; XOD: xanthine oxidase

\section{Acknowledgements}

Not applicable.

\section{Funding}

This research was supported by a grant of the Korea Health Technology R\&D Project through the Korea Health Industry Development Institute (KHIDI), funded by the Ministry of Health \& Welfare, Republic of Korea (grant number: HI17C0911).

\section{Availability of data and materials}

The datasets used and/or analyzed during the current study are available from the corresponding author on reasonable request.

\section{Authors' contributions}

$\mathrm{OD}, \mathrm{KJR}$, and KBY carried out all the assays. CC, NC, and CCY participated in the design of the study and performed the statistical analysis. KYR and KS participated in designing and coordinating the study and helped in drafting the manuscript. All the authors read and approved the final manuscript.

\section{Ethics approval and consent to participate}

All the animal procedures were carried out in accordance with the guidelines of the Animal Care and Use Committee of Chonnam National University. The animal study was approved by Animal Care and Use Committee of Chonnam National University (Permission number: CNN IACUC-YB-2016-12).

\section{Consent for publication}

Not applicable.

\section{Competing interests}

The authors declare that they have no competing interests.

\section{Publisher's Note}

Springer Nature remains neutral with regard to jurisdictional claims in published maps and institutional affiliations.

\section{Author details}

${ }^{1}$ College of Pharmacy and Research Institute of Drug Development, Chonnam National University, Gwangju 61186, Republic of Korea. ${ }^{2}$ Jeonnam Bioindustry Foundation, Jeollanamdo Institute of Natural Resources Research (JINR), Jeonnam 59338, Republic of Korea. ${ }^{3}$ MEGA BIO Co., Ltd, Jeonnam 58141, Republic of Korea. ${ }^{4}$ College of Korean Medicine, Dongshin University, 185 Geonjae-ro, Naju-si, Jeollanam-do 58245, Republic of Korea. ${ }^{5}$ Department of Korean Medicine Rehabilitation, Mokpo Oriental Hospital of Dongshin University, 313 Baengnyeon-daero, Mokpo 530-822, South Korea.

Received: 1 December 2017 Accepted: 19 December 2018 Published online: 08 January 2019

References

1. Haidari F, Rashidi MR, Keshavarz SA, Mahboob SA, Eshraghian MR, Shahi MM. Effects of onion on serum uric acid levels and hepatic xanthine dehydrogenase/xanthine oxidase activities in hyperuricemic rats. Pak J Biol Sci. 2008;11(14):1779-84.

2. Chen JHCS, Chen HJ, Yeh WT, Pan WH. Serum uric acid level as an independent risk factor for all-cause, cardiovascular, and ischemic stroke mortality: a Chinese cohort study. Arthritis Rheum. 2009;61:225-32.

3. Graessler J, Graessler A, Unger S, Kopprasch S, Tausche AK, Kuhlisch E, Schroeder HE. Association of the human urate transporter 1 with reduced renal uric acid excretion and hyperuricemia in a German Caucasian population. Arthritis Rheum. 2006;54(1):292-300. 
4. Vazquez-Mellado J, Jimenez-Vaca AL, Cuevas-Covarrubias S, AlvaradoRomano V, Pozo-Molina G, Burgos-Vargas R. Molecular analysis of the SLC22A12 (URAT1) gene in patients with primary gout. Rheumatology. 2007:46(2):215-9.

5. Umamaheswari M, Asokkumar K, Sivashanmugam AT, Remyaraju A, Subhadradevi $\vee$, Ravi TK. In vitro xanthine oxidase inhibitory activity of the fractions of Erythrina stricta Roxb. J Ethnopharmacol. 2009;124(3):646-8.

6. Cronstein BN, Terkeltaub R. The inflammatory process of gout and its treatment. Arthritis Res Ther. 2006;8(Suppl 1):S3.

7. Kim YH, Lee JH. CheongKangEuiGam. Seoul: Seongbosa; 2001. p. 315.

8. Jeoung BR, Lee KD, Na CS, Kim YE, Kim B, Kim YR. Ganghwaljetongyeum, an anti-arthritic remedy, attenuates synoviocyte proliferation and reduces the production of proinflammatory mediators in macrophages: the therapeutic effect of GHJTY on rheumatoid arthritis. BMC Complemen Altern Med. 2013;13:47.

9. Choi W, Choi CH, Kim YR, Kim SJ, Na CS, Lee H. HerDing: herb recommendation system to treat diseases using genes and chemicals. Database (Oxford). 2016;2016:1-7.

10. Park JU, Kim SJ, Na CS, Choi CH, Seo CS, Son JK, Kang BY, Kim YR. Chondroprotective and anti-inflammatory effects of ChondroT, a new complex herbal medication. BMC Complem Altern Med. 2016;16:213.

11. Sun Y, Brenner H, Sauerland S, Gunther KP, Puhl W, Sturmer T. Serum uric acid and patterns of radiographic osteoarthritis--the Ulm osteoarthritis study. Scand J Rheumatol. 2000;29(6):380-6.

12. Acheson RM, Collart AB. New Haven survey of joint diseases. XVII. Relationship between some systemic characteristics and osteoarthrosis in a general population. Ann Rheum Dis. 1975;34(5):379-87.

13. Denoble AEHK, Stabler TV, Kelly SJ, Hershfield MS, McDaniel GE, Coleman $R E$, Kraus VB. Uric acid is a danger signal of increasing risk for osteoarthritis through inflammasome activation. Proc Natl Acad Sci U S A. 2011;108:2088-93.

14. Nowatzky J, Howard R, Pillinger MH, Krasnokutsky S. The role of uric acid and other crystals in osteoarthritis. Curr Rheumatol Rep. 2010;12(2):142-8.

15. Wang SY, Yang CW, Liao JW, Zhen WW, Chu FH, Chang ST. Essential oil from leaves of Cinnamomum osmophloeum acts as a xanthine oxidase inhibitor and reduces the serum uric acid levels in oxonate-induced mice. Phytomedicine. 2008;15:940-5.

16. Stavric B, Clayman S, Gradd RE, Hebert D. Some in vivo effects in the rat induced by chlorprothixene and potassium oxonate. Pharmacol Res Commun. 1975;7:117-24.

17. Hall IH, Scoville JP, Reynolds DJ, Simlot R, Duncan P. Substituted cyclic imides as potential anti-gout agents. Life Sci. 1990;46:1923-7.

18. Wang X, Wang C, Hu Q, LV Y, Zhang X, Ouyang Z, Kong L. The dual actions of Sanmiao wan as a hypouricemic agent: Down-regulation of hepatic XOD and renal mURAT1 in hyperuricemic mice. J Ethnopharmacol. 2010; 128(1):107-15.

19. Mohammadi A, Mirzaei F, Jamshidi M, Yari R, Pak S, Norouzian P, Abdolkarimi V, Oshaghi EA. Influence of flaxseed on lipid profiles and expression of LXRa, in intestine of diabetic rat. Int J Biol. 2013;5(4):23-8.

20. Mohammadi A, Vafaei SA, Moradi MN, Ahmadi M, Pourjafar M, Oshaghi EA. Combination of ezetimibe and garlic reduces serum lipids and intestinal Niemann-pick C1-like 1 expression more effectively in Hypercholesterolemic mice. Avicenna J Med Biochem. 2015;3(1):e23205.

21. Elion GB, Kovensky A, Hitchings GH. Metabolic studies of allopurinol, an inhibitor of xanthine oxidase. Biochem Pharmacol. 1966;15(7):863-80.

22. Takano Y, Hase-Aoki K, Horiuchi H, Zhao L, Kasahara Y, Kondo S, Becker MA. Selectivity of febuxostat, a novel non-purine inhibitor of xanthine oxidase/ xanthine dehydrogenase. Life Sci. 2005;76(16):1835-47.

23. Bisht M, Bist SS. Febuxostat: a novel agent for management of hyperuricemia in gout. Indian J Pharm Sci. 2011;73(6):597-600.

24. Hoffmann D, Fuchs TC, Henzler T, Matheis KA, Herget T, Dekant W, Hewitt P, Mally A. Evaluation of a urinary kidney biomarker panel in rat models of acute and subchronic nephrotoxicity. Toxicology. 2010;277(1-3):49-58.

25. Kang DH, Nakagawa T, Feng L, Watanabe S, Han L, Mazzali M, Truong L, Harris R, Johnson RJ. A role for uric acid in the progression of renal disease. J Am Soci Nephrol. 2002;13(12):2888-97.

26. Siu YP, Leung KT, Tong MK, Kwan TH. Use of allopurinol in slowing the progression of renal disease through its ability to lower serum uric acid level. Am J Kidney Dis. 2006:47:51-9.

27. Tomita M, Mizuno S, Yamanaka H, Hosoda Y, Sakuma K, Matuoka Y, Odaka M, Yamaguchi M, Yosida H, Morisawa $H$, et al. Does hyperuricemia aeffect mortality? A prospective cohort study of japanese male workers. J Epidemiol. 2000;10:403-9.

28. Richette P, Bardin T. Gout. Lancet. 2010;375(9711):318-28.

29. Kong LD, Yang C, Ge F, Wang HD, Guo YS. A Chinese herbal medicine Ermiao wan reduces serum uric acid level and inhibits liver xanthine dehydrogenase and xanthine oxidase in mice. J Ethnopharmacol. 2004; 93(2-3):325-30.

30. Kim JH, Huh JE, Baek YH, Lee JD, Choi DY, Park DS. Effect of Phellodendron amurense in protecting human osteoarthritic cartilage and chondrocytes. J Ethnopharmacol. 2011;134(2):234-42.

31. Shin YJ, Hwang JM, Lee SC. Antioxidant and xanthine oxidase inhibitory activities of hot water extracts of medicinal herbs. J Korean Soc Food Sci Nutr. 2013;42(10):1712-6.

32. Lee JS, Kim KH, Lee SD, Kim KS. The effect of Clematidis Radix herbalacupuncture solution, on collagen, adjuvant, lipopolysaccharide and phospholipase A2 induced rheumatoid arthritis in mice. J Korean Acupunct Moxibustion Society. 2012;29(1):127-37.

33. Meng ZQ, Tang ZH, Yan YX, Guo CR, Cao L, Ding G, Huang WZ, Wang ZZ, Wang KD, Xiao W, et al. Study on the anti-gout activity of chlorogenic acid: improvement on hyperuricemia and gouty inflammation. Am J Chin Med. 2014:42(6):1471-83.

34. Ahmad I, ljaz F, Fatima I, Ahmad N, Chen S, Afza N, Malik A. Xanthine oxidase/tyrosinase inhibiting, antioxidant, and antifungal oxindole alkaloids from Isatis costata. Pharm Biol. 2010;48(6):716-21.

\section{Ready to submit your research? Choose BMC and benefit from:}

- fast, convenient online submission

- thorough peer review by experienced researchers in your field

- rapid publication on acceptance

- support for research data, including large and complex data types

- gold Open Access which fosters wider collaboration and increased citations

- maximum visibility for your research: over $100 \mathrm{M}$ website views per year

At BMC, research is always in progress.

Learn more biomedcentral.com/submissions 